\title{
CONTROLE DA FUSARIOSE EM PLANTAS DE PIMENTA-DO-REINO COM BACTÉRIAS ENDOFÍTICAS: SOBREVIVÊNCIAE RESPOSTAS MORFOFISIOLÓGICAS ${ }^{1}$
}

\author{
RUTH LINDA BENCHIMOL ${ }^{2}$, ELIZABETH YING $\mathrm{CHU}^{3}, \mathrm{ROBERTO}$ YUITIMUTO ${ }^{4}$ \\ e MOACYR BERNARDINO DIAS-FILHO ${ }^{5}$
}

\begin{abstract}
RESUMO - Oito bactérias endofíticas de plântulas de pimenta-do-reino foram testadas em casa de vegetação, objetivando controlar Fusarium solani f. sp. piperis e avaliar respostas morfofisiológicas das plantas tratadas com os agentes de controle. Plantas com quatro meses de idade tiveram o sistema radicular tratado com as suspensões bacterianas $\left(10^{9} \mathrm{ufc} \mathrm{mL}^{-1}\right)$ por 10 minutos, e foram plantadas em vasos com solo natural infestado artificialmente com o patógeno $(0,25 \%)$. O delineamento experimental foi inteiramente casualizado, com três repetições para avaliar o comportamento fotossintético, a produção e a alocação de biomassa, e cinco repetições para avaliar a mortalidade das plantas. As avaliações foram feitas 120 dias após a instalação do ensaio. O isolado B0 (Methylobacterium radiotolerans) controlou $F$. solani f. sp. piperis, provocando redução significativa do número de plantas mortas. Na ausência do patógeno, M. radiotolerans funcionou ainda como promotor de crescimento. Os demais isolados testados não apresentaram efeito na diminuição da mortalidade das plantas. A aplicação das bactérias endofíticas não afetou a taxa fotossintética instantânea das plantas, à exceção de B6, que teve efeito negativo. As plantas tratadas $\operatorname{com} M$. radiotolerans priorizaram a alocação de carbono para a parte aérea.
\end{abstract}

Termos para indexação: patógenos, Fusarium solani, métodos de controle de pragas, técnicas de isolamento, agentes de controle biológico, fotossíntese, biomassa.

\section{FUSARIOSIS CONTROL IN BLACK PEPPER PLANTS WITH BACTERIAL ENDOPHYTES SURVIVAL AND MORPHOPHYSIOLOGICAL RESPONSES}

ABSTRACT - Eight endophytic bacteria from black pepper seedlings were tested under greenhouse conditions aiming to control Fusarium solani f. sp. piperis and to evaluate some morphophysiological responses in plants treated with the biocontrol agents. Four-month old plants had their roots treated with the bacterial suspensions $\left(10^{9} \mathrm{cfu} \mathrm{mL}^{-1}\right)$ for 10 minutes and were planted in pots containing soil artificially infested with the pathogen $(0.25 \%)$. The experimental design was completely randomized, with three replications to evaluate photosynthetic behavior, and biomass production and allocation, and five replications to evaluate plant mortality. Evaluations were made 120 days after the establishment of the experiment. The isolate B0 (Methylobacterium radiotolerans) significantly reduced seedling mortality by fusariosis. No significant effect in seedling mortality reduction could be detected for the other bacterial isolates. In the absence of the pathogen, $M$. radiotolerans acted as a plant growth promoter. The application of the bacterial endophytes had no effect on the instantaneous photosynthetic rate, with the exception of $\mathrm{B} 6$, that had a negative effect. Plants treated with M. radiotolerans allocated carbon preferentially to the above ground tissues.

Index terms: pathogens, Fusarium solani, pest control methods, isolation techniques, biological control organisms, photosynthesis, biomass.

\footnotetext{
${ }^{1}$ Aceito para publicação em 29 de novembro de 1999.

${ }^{2}$ Eng. Agrôn., M.Sc., Embrapa-Centro de Pesquisa Agroflorestal da Amazônia Oriental (CPATU), Caixa Postal 48 CEP 66017-970 Belém, PA.

E-mail: rlinda@cpatu.embrapa.br

${ }^{3}$ Eng. Agrôn., M.Sc., Embrapa-CPATU.

E-mail: beth.bel@zaz.com.br

${ }^{4}$ Aluno do Curso de Agronomia. Bolsista do PIBIC/CNPq Embrapa-CPATU

${ }^{5}$ Eng. Agrôn., Ph.D., Embrapa-CPATU. Bolsista do CNPq.

E-mail: moacyr@cpatu.embrapa.br
}

\section{INTRODUÇÃO}

A fusariose da pimenta-do-reino (Piper nigrum L.), provocada por Fusarium solani f. sp. piperis Albuquerque, tem causado ao longo dos últimos 30 anos, a redução da vida útil dos pimentais na região amazônica, de 12 a 15 anos para quatro a seis anos (Albuquerque, 1961; Duarte \& Albuquerque, 1986; Hamada et al., 1988). 
As medidas que vêm sendo adotadas para o controle da fusariose, como práticas culturais, obtenção de variedades resistentes e aplicação de fungicidas (Duarte \& Albuquerque, 1980; Albuquerque et al., 1997; Ando et al., 1997), têm-se mostrado onerosas ou pouco eficientes. Isso mostra a necessidade do desenvolvimento de novos métodos de controle, entre os quais o controle biológico, através da utilização de microorganismos benéficos (Cook \& Baker, 1983; Baker, 1987), o qual tem sido apontado como opção viável diante da biodiversidade inexplorada existente na Amazônia (Stein et al., 1996; Endo et al., 1997).

A associação de plantas com bactérias benéficas vem adquirindo importância crescente no biocontrole de doenças das plantas. Sabe-se que algumas bactérias, mais especificamente as rizobactérias promotoras de crescimento em plantas (RPCP), além de terem efeito como promotoras de crescimento, contribuindo para aumentar a capacidade competitiva do hospedeiro (Kloepper \& Schroth, 1978; Défago et al., 1990; Schroth \& Becker, 1990; Bakker et al., 1991; Schippers et al., 1991; Luz, 1996), podem ainda funcionar como agentes de controle biológico (Schippers, 1988; Weller, 1988; Luz, 1991, 1993; Schippers et al., 1991; Kloepper, 1993).

O comportamento fisiológico de plantas tratadas com agentes de biocontrole vem sendo estudado, visando comprovar mudanças fisiológicas associadas a infecções provocadas por determinados patógenos (Zhang et al., 1996).

O objetivo deste estudo foi testar, sob condições semicontroladas de casa de vegetação, o efeito de bactérias endofíticas isoladas do hipocótilo de plantas de pimenta-do-reino na redução da mortalidade causada pela fusariose e no comportamento morfofisiológico desse hospedeiro.

\section{MATERIAL E MÉTODOS}

O experimento foi conduzido em Belém, PA, no Campo Experimental da Embrapa-Centro de Pesquisa Agroflorestal da Amazônia Oriental (CPATU) (1 ${ }^{\circ} 28^{\prime} \mathrm{S}$; $48^{\circ} 27^{\prime} \mathrm{W}$ ), em condições de casa de vegetação com $50 \%$ de interceptação da luz solar, com temperatura e umidade relativa do ar na faixa de $25-35^{\circ} \mathrm{C}$ e $80-95 \%$, respectivamente.
Oito isolados bacterianos (B0, B1, B2, B3, B4, B5, B6 e B7) foram obtidos através de plaqueamento nos meios de NA (Bacto Nutrient Agar, Difco, EUA) + tropolone (Wako Pure Chemical, Japão), KMB (Meio de King B, Eiken Chemical, Japão) e NA, de uma alíquota de macerado (peptona 2\%) do hipocótilo de plântulas sobreviventes de pimenta-do-reino, variedade Guajarina, cujo sistema radicular, removido no estádio de duas folhas verdadeiras, foi regenerado em bandejas $(47 \times 34 \times 11 \mathrm{~cm})$ com solo contendo $0,25 \%$ de solo-inóculo (solo peneirado + farelo de trigo, 4:1 v/v) de F. solani f. sp. piperis (FSP). Após incubação de 24 a 72 horas, os isolados obtidos foram preservados em skim milk (Wako Pure Chemical, Japão) a 10\%, em deep freezer $\left(-31^{\circ} \mathrm{C}\right)$, até sua utilização.

Para o preparo das suspensões de inoculação, culturas de cada um dos isolados bacterianos foram preparadas em placas de Petri contendo NA, incubadas a $24^{\circ} \mathrm{C}$, em regime de luz alternado ( 12 horas luz/12 horas escuro). Após 48 horas de incubação, suspensões aquosas das culturas bacterianas foram centrifugadas (15 minutos; $3.000 \mathrm{rpm}$ ) e os precipitados ressuspensos em água destilada esterilizada. A concentração final das suspensões foi ajustada para $10^{9}$ ufc $\mathrm{mL}^{-1}$ (Front Scatter Method Turbidimeter UT-11, a $550 \mathrm{~nm}$ )

Dos isolados testados, apenas B0, B5 e B6 foram identificados como pertencentes às espécies Methylobacterium raditolerans (anteriormente denominada Pseudomonas radiora), Brevibacterium linens/epidermis e Achromobacter xylosoxydans subsp. xylosoxydans (anteriormente denominada Alcaligenes xylosoxydans subsp. xylosoxydans), respectivamente.

Foram utilizadas plantas de pimenta-do-reino, variedade Guajarina, com quatro meses de idade, originadas de sementes germinadas em areia lavada, colhidas de matrizes mantidas no Banco de Germoplasma do Campo Experimental da Embrapa-CPATU, em Belém, PA.

$\mathrm{O}$ isolado patogênico de Fusarium solani f. sp. piperis (FSP) utilizado nos testes de controle biológico foi obtido em Belém, durante a estação chuvosa de 1997. Discos de cultura $(\varnothing=5 \mathrm{~mm})$ de FSP em Batata Sacarose Ágar (BSA) foram plantados em erlenmeyers contendo mistura autoclavada $\left(1\right.$ hora; $\left.120^{\circ} \mathrm{C}\right)$ de solo peneirado + farelo de trigo $(4: 1 \mathrm{v} / \mathrm{v})$. Após 15 dias de incubação (12 horas luz/ 12 horas escuro; $\left.24^{\circ} \mathrm{C}\right)$, o inóculo foi misturado $(0,25 \%)$ com solo de mata peneirado, para envasamento, no dia da instalação do experimento. Foram utilizados vasos de plástico com capacidade para $2 \mathrm{~kg}$ de solo.

Para a montagem do ensaio em casa de vegetação, o sistema radicular das plantas foi imergido nas suspensões bacterianas durante dez minutos, processo conhecido como bacterização, após o que as plantas foram imediatamente 
plantadas em vasos contendo solo infectado com FSP (três plantas por vaso; cinco vasos por tratamento), constituindo os tratamentos FB0, FB1, FB2, FB3, FB4, FB5, FB6 e FB7. Plantas não bacterizadas foram mantidas em solo infectado com o patógeno, constituindo o tratamento $\mathrm{TF}$ (testemunha do patógeno). As plantas tratadas somente com os isolados bacterianos e mantidas em vasos contendo solo livre do patógeno constituíram os tratamentos TB0, TB1, TB2, TB3, TB4, TB5, TB6 e TB7. Plantas não bacterizadas e mantidas em solo livre do patógeno constituíram o tratamento TA (testemunha absoluta). Após 120 dias, foram avaliados o número de plantas sobreviventes, o comportamento fotossintético e a alocação de biomassa das plantas tratadas e não tratadas

Para a avaliação do comportamento fotossintético das plantas, utilizou-se a folha mais nova, intacta e completamente desenvolvida, de uma planta por vaso. As medições foram feitas no horário das $9 \mathrm{~h}$ às $11 \mathrm{~h}$, utilizando um sistema de fotossíntese portátil (Modelo LI-6200, LI-COR Inc., Lincoln, NE, EUA). Os parâmetros de troca gasosa foram calculados com base na área foliar.

A produção de massa seca foi avaliada ao final do experimento, através da determinação da massa seca de folhas, hastes e raízes de cada planta, em estufa a $70^{\circ} \mathrm{C}$, por 48 horas. Esses dados foram usados para o cálculo dos padrões de alocação de biomassa, isto é, as razões da massa das folhas, da haste e das raízes por unidade de massa da planta inteira.

$\mathrm{O}$ delineamento experimental foi inteiramente casualizado, com três repetições, com relação ao comportamento fotossintético, produção e alocação de biomassa, e cinco repetições para mortalidade de plantas.

Os dados foram submetidos a análise de variância (ANOVA) e, quando apropriado, as médias foram comparadas pelo teste de Duncan. Em cada ANOVA, a homogeneidade da variância foi testada pelo teste de Levene. O programa estatístico Statistica para Windows versão 5.0 (Statistica..., 1995) foi utilizado em todos os cálculos estatísticos e na construção de gráficos.

\section{RESULTADOS E DISCUSSÃO}

De modo geral, os efeitos das bactérias testadas sobre as plantas de pimenta-do-reino, tanto em relação ao controle de FSP, como no crescimento, fotossíntese e alocação de biomassa, foram bastante variáveis.

Schippers et al. (1987), referindo-se às RPCP, classificaram os diferentes efeitos provocados por esses agentes nas plantas como deletérios, neutros ou benéficos, estes últimos através de estímulo ao crescimento ou de proteção microbiológica. Essas situações foram detectadas nas plantas de pimenta-doreino tratadas com os isolados bacterianos endofíticos testados.

Resultados do teste de Duncan (Fig. 1) mostraram que FB0 (mudas bacterizadas com B0, em solo com FSP), quando comparado a TF (mudas não bacterizadas, em solo com FSP), foi superior aos demais tratamentos no tocante à proteção contra o patógeno, proporcionando redução significativa $(\mathrm{p}=0,037)$ no número de plantas mortas. Embora com efeito estatisticamente semelhante $(p=0,62)$ a FB0, FB7 não diferiu $(p=0,095)$ de TF.

Os isolados B2 e B4 (Fig. 1) tiveram efeito deletério, aumentando significativamente $(\mathrm{p}=0,026 \mathrm{e}$ $\mathrm{p}=0,002)$ a mortalidade das mudas tratadas com os mesmos, em comparação com TF, e inclusive com TA $(p=0,043)$, para B4. Não foi possível detectar efeito significativo dos demais isolados testados na mortalidade de mudas de pimenta-do-reino, sendo, portanto, considerados de efeito neutro (Fig. 1)

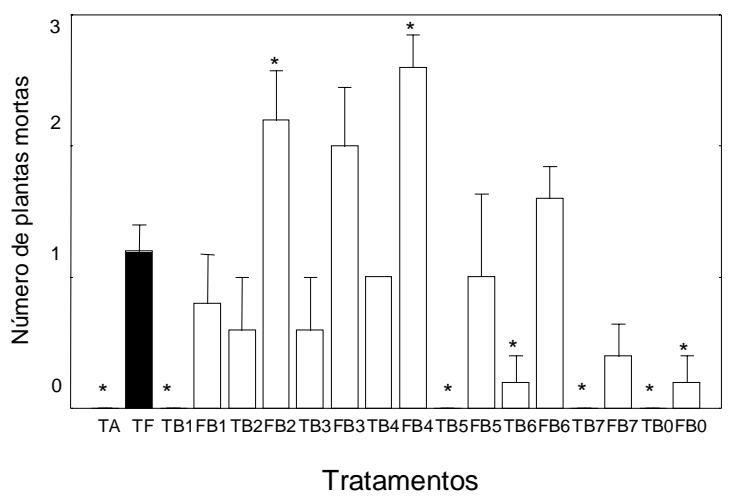

FIG. 1. Mortalidade de plantas de pimenta-do-reino tratadas com os isolados B0, B1, B2, B3, B4, B5, B6 e B7 de bactérias endofíticas, em solo infestado com $F$. solani $\mathrm{f}$. sp. piperis (FSP). FB: FSP x bactéria; TB: testemunha bactéria; TF: testemunha patógeno; TA: testemunha absoluta. Os asteriscos indicam diferença significativa $(p<0,05)$ em relação a TF (barra escura), de acordo com o teste de Duncan. Os valores são média \pm erro padrão; $\mathbf{n}=\mathbf{5}$.

Pesq. agropec. bras., Brasília, v.35, n.7, p.1343-1348, jul. 2000 
Plantas tratadas com o isolado B0, na presença ou ausência do patógeno, apresentaram produção de massa seca da parte aérea superior a TA (Fig. 2). Portanto, é possível afirmar que esse isolado teve efeito positivo no crescimento das plantas, atuando como promotor de crescimento (Luz, 1991; Schippers et al., 1991; Kloepper, 1993). Embora não tendo sido possível detectar diferenças, dentro dos critérios estatísticos adotados, é possível observar, na Fig. 2, que os isolados B1, B5 e B7 apresentaram tendências a efeitos semelhantes ao de $\mathrm{B} 0$.

Observou-se, de modo geral, tendência das plantas bacterizadas a priorizar a alocação de $\mathrm{C}$ para a parte aérea, em detrimento do sistema radicular (Figs. $2 \mathrm{e}$ ), principalmente para as folhas, sugerindo possivel efeito benéfico desses isolados na aquisição de nutrientes (provavelmente $\mathrm{N}$ ) pelas plantas, tanto na ausência como na presença do patógeno.
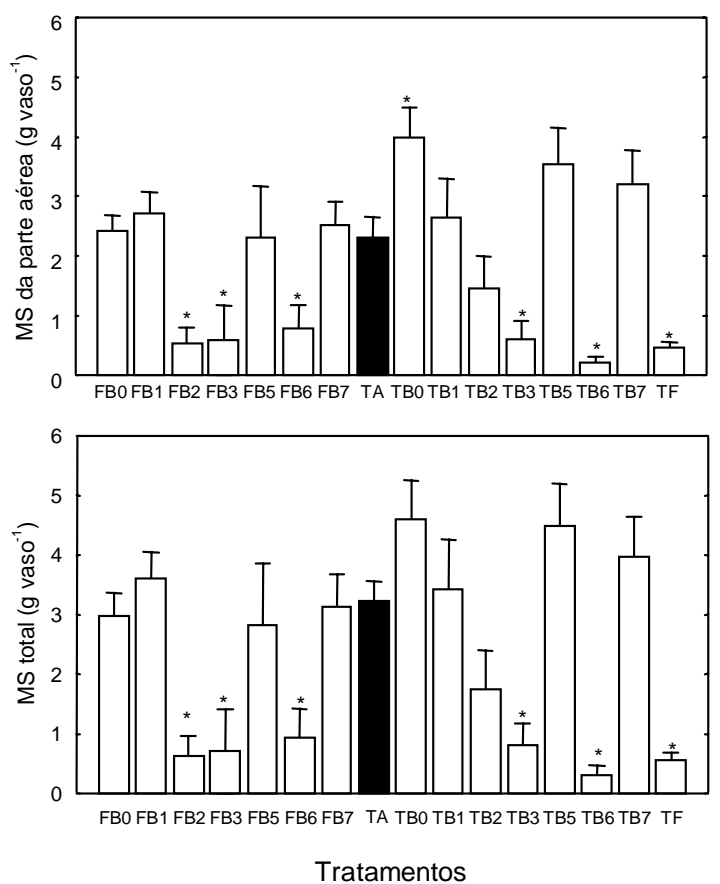

FIG. 2. Produção de massa seca (MS) da parte aérea e total de plantas de pimenta-do-reino. Tratamentos conforme a Fig. 1. Os asteriscos indicam diferença significativa $(p<0,05)$ em relação a TA (barra escura), de acordo com o teste de Duncan. Os valores são média \pm erro padrão; $\mathbf{n}=\mathbf{3}$.
Esse fato foi particularmente evidente nas plantas tratadas com B0. Uma característica de plantas com alto suprimento de $\mathrm{N}$ é o aumento da alocação de biomassa para a parte aérea, principalmente para as folhas, em função da menor necessidade de produção de raízes para a absorção daquele nutriente (Fichtner et al., 1995).

A Fig. 4 mostra que, em geral, o comportamento fotossintético instantâneo das plantas foi satisfatório, embora não tenha sido possível detectar efeito significativo dos tratamentos com os isolados bacterianos em relação aos tratamentos TAe TF.

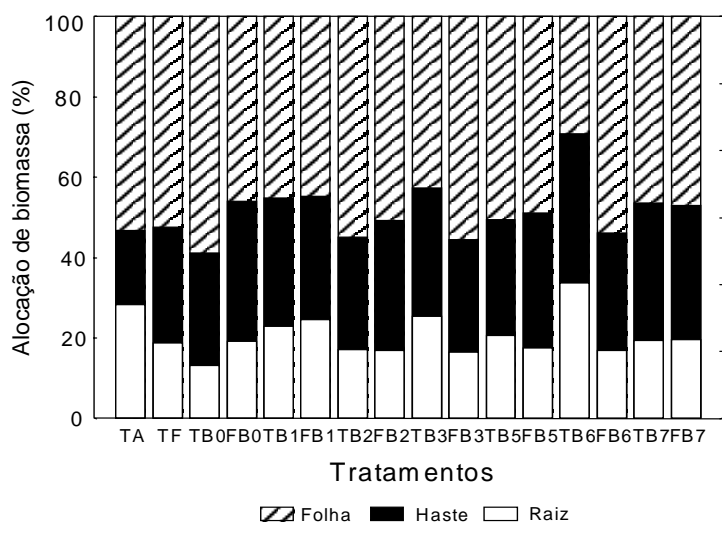

FIG. 3. Alocação de biomassa em plantas de pimenta-do-reino. Tratamentos conforme a Fig. 1.

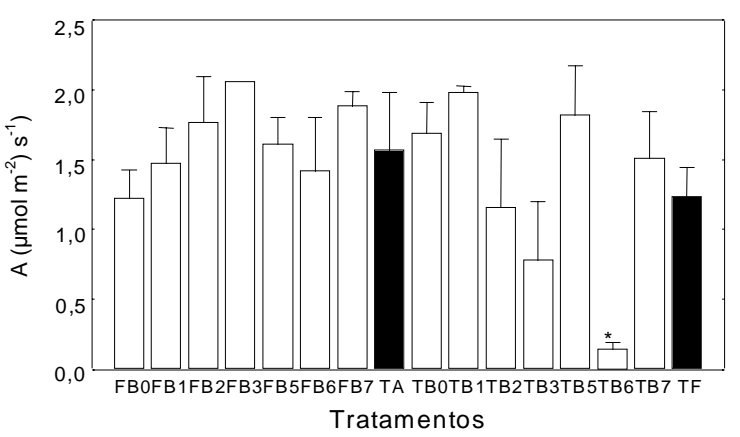

FIG. 4. Fotossíntese líquida (A) de plantas de pimenta-do-reino. Tratamentos conforme a Fig. 1. $O$ asterisco indica diferença significativa $(\mathbf{p}<0,05)$ em relação a TA e TF (barras escuras), de acordo com o teste de Duncan. Os valores são média \pm erro padrão; $\mathbf{n}=3$. 
O comportamento fotossintético satisfatório em $\mathrm{TF}$ pode ser explicado pelo fato de este ter sido medido nas plantas sobreviventes, isto é, ainda sem manifestação dos sintomas de fusariose. Resultados obtidos por Zhang et al. (1996) demonstraram que a aplicação de Gliocladium roseum Bainier como agente de controle biológico de Botrytis cinerea Pers. Fr. em Picea mariana (Mill.) B.S.P. evitou decréscimos significativos na taxa fotossintética das plântulas. A fotossíntese das plantas tratadas com o isolado B6 foi, no entanto, significativamente inferior à das demais, refletindo a baixa produção de massa seca total e da parte aérea (Fig. 2) das plantas tratadas com esse isolado.

\section{CONCLUSÕES}

1. O isolado B0 (Methylobacterium radiotolerans) atua como agente de controle de F. solani f. sp. piperis; os isolados B2 e B4 (não identificados) têm efeito deletério, e os demais isolados testados têm efeito neutro na diminuição da mortalidade de plantas de pimenta-do-reino.

2. Na ausência do patógeno, M. radiotolerans funciona como promotor de crescimento da parte aérea em mudas de pimenta-do-reino.

3. As mudas tratadas com $M$. radiotolerans tendem a priorizar a alocação de $\mathrm{C}$ para a parte aérea, tanto na presença como na ausência do patógeno.

\section{AGRADECIMENTOS}

A Joseph W. Kloepper e John McInroy, Universidade de Auburn, AL, EUA, pela identificação dos isolados; a Toshio Kijima, Tochigi Prefectural Agricultural Experiment Station, Utsunomyia, Japão/ JICA, pela orientação nos métodos de isolamento e teste dos isolados bacterianos; a Ivanildo Trindade, pelo auxílio nas avaliações de fotossíntese; a José Maria de Souza, Aloísio Chagas Júnior e Luciene Favacho Barbosa, pelo auxílio nas avaliações de alocação de biomassa; a um revisor anônimo, pelas sugestões para melhoria do trabalho.

\section{REFERÊNCIAS}

ALBUQUERQUE, F.C. Podridão das raízes e do pé da pimenta-do-reino. Belém : IPEAN, 1961. 45p. (IPEAN. Circular, 5).

ALBUQUERQUE, F.C.; DUARTE, M.L.R.; NUNES, A.M.L.; STEIN, R.L.B.; OLIVEIRA, R.P. Comportamento de germoplasma de pimenta-do-reino em áreas de ocorrência de fusariose no Estado do Pará. In: SEMINÁRIO INTERNACIONAL SOBRE PIMENTA E CUPUAÇU, 1., 1996, Belém. Anais. Belém : Embrapa-CPATU/JCA, 1997. p.269-276. (Embrapa-CPATU. Documentos, 89).

ANDO, A.; ALBUQUERQUE, F.C.; POLTRONIERI, M.C.; TULMANN NETO, A. Obtenção de mutantes resistentes à fusariose (Fusarium solani f. sp. piperis) em pimenta-do-reino através de irradiação gama. In: SEMINÁRIO INTERNACIONAL SOBRE PIMENTA E CUPUAÇU, 1., 1996, Belém. Anais. Belém : Embrapa-CPATU/JICA, 1997. p.237-243. (Embrapa-CPATU. Documentos, 89)

BAKER, K.F. Evolving concepts of biological control of plant pathogens. Annual Review of Phytopathology, Palo Alto, v.25, p.67-85,1987.

BAKKER, P.A.H.M.; PEER, R. van; SCHIPPERS, B Suppression of soil-borne plant pathogens by fluorescent pseudomonads: mechanisms and prospects. In: BEEMSTER, A.B.R.; BOLLEN, G.J.; GERLAGH, M.; RUISSEN, M.A.; SCHIPPERS, B.; TEMPEL, A. (Ed.). Biotic interactions and soil-borne diseases. Amsterdam : Elsevier, 1991. p.217-223.

COOK, R.J.; BAKER, K.F. Nature and practice of biological control of plant pathogens. Saint Paul : American Phytopathological Society, 1983. 539p.

DÉFAGO, G.; BERLING, C.H.; BURGER, U.; HAAS, D.; KAHR, G.; KEEL, C.; VOISARD, C.; WIRTHNER, P.H.; WÜTHRICH, B. Suppression of black root rot of tobacco by a Pseudomonas strain potential applications and mechanisms. In HORNBY, D.; COOK, R.J.; HENIS, Y. (Ed.). Biological control of soil-borne plant pathogens Wallingford: CAB International, 1990. p.93-108.

DUARTE, M.L.R.; ALBUQUERQUE, F.C. Eficiência de diferentes fungicidas no tratamento de estacas de pimenta-do-reino (Piper nigrum L.) infectadas por Nectria haematococca (Fusarium solani f. sp. piperis). Fitopatologia Brasileira, Brasília, v.6, n.2, p.169-175, 1980

Pesq. agropec. bras., Brasília, v.35, n.7, p.1343-1348, jul. 2000 
DUARTE, M.L.R.; ALBUQUERQUE, F.C. Secamento dos ramos da pimenta-do-reino. In: SIMPÓSIO DO TRÓPICO ÚMIDO, 1., 1984, Belém. Anais. Brasília Embrapa-DDT, 1986. v.4, p.383-394.

ENDO, T.; STEIN, R.L.B.; CHU, E.Y.; ALBUQUERQUE, F.C. Controle biológico da fusariose da pimenta-do-reino In: SEMINÁRIO INTERNACIONAL SOBRE PIMENTA E CUPUAÇU, 1., 1996, Belém. Anais. Belém : Embrapa-CPATU/JICA, 1997. p.395-406. (Embrapa-CPATU. Documentos, 89).

FICHTNER, K.; KOCH, G.W.; MOONEY, H.A. Photosynthesis, storage and allocation. In SCHULZE, E.D.; CALDWELL, M.M. (Ed.) Ecophysiology of photosynthesis. Berlin : Springer, 1995. p.132-146.

HAMADA, M.; UCHIDA,T;; TSUDA, M. Ascospore dispersal of the causal agent of Nectria blight of Piper nigrum. Phytopathological Society of Japan Annals, Tokyo, v.54, p.303-308, 1988.

KLOEPPER, J.W. Plant growth-promoting rhizobacteria as biological control agents of soil-borne diseases. In: METTING, B. (Ed.). Soil microbial technologies. New York : M. Dekker, 1993. p.255274.

KLOEPPER, J.W.; SCHROTH, M.N. Plant growthpromoting rhizobacteria on radishes. In INTERNATIONAL CONFERENCE ON PLANT PATHOGENIC BACTERIA, 4., 1978, Angers Proceedings. Angers : Institut National de la Recherche, 1978. v.2, p.879-882

LUZ, W.C. Controle biológico das doenças na espermosfera. In: EMBRAPA. Centro Nacional de Pesquisa de Defensivos Agrícolas (Jaguariúna, SP) Controle biológico de doenças de plantas. Jaguariúna, 1991. p.25-31.

LUZ, W.C. Microbiolização de sementes para o controle de doenças das plantas. Revisão Anual de Patologia de Plantas, Passo Fundo, v.1, p.35-77, 1993

LUZ, W.C. Rizobactérias promotoras do crescimento de plantas e de bioproteção. Revisão Anual de Patologia de Plantas, Passo Fundo, v.4, p.1-49, 1996.
SCHIPPERS, B. Biological control of pathogens with rhizobacteria. Royal Society of London Philosophical Transactions, London, v.318, p.283293, 1988

SCHIPPERS, B.; BAKKER, A.W.; BAKKER, P.A.H.M Interactions of deleterious and beneficial rhizosphere microorganisms and the effect of cropping practices. Annual Review of Phytopathology, PaloAlto, v.25, p.339-358, 1987.

SCHIPPERS, B.; BAKKER, A.W.; BAKKER, P.A.H.M.; PEER, R. van. Beneficial and deleterious effects of $\mathrm{HCN}$-producing pseudomonads on rhizosphere interactions. In: KEISTER, D.L.; CREGAN, P.B. (Ed.). The rhizosphere and plant growth Dordrecth : Kluwer Academic, 1991. p.211-220.

SCHROTH, M.N.; BECKER, J.O. Concepts of ecological and physiological activities of rhizosphere related to biological and plant growth promoting. In: HORNBY, D.; COOK, R.J.; HENIS, Y. (Ed.). Biological control of soil-borne plant pathogens. Wallingford CAB International, 1990. p.389-414

STATISTICA for windows: general conventions and statistics. Tulsa : StatSoft, 1995. v.1.

STEIN, R.L.B.;ALBUQUERQUE, F.C.; CHU, E.Y.; ABE, Z.; YONEYAMA, S.; ENDO, T. Levantamento de microorganismos potencialmente ativos contra Fusarium solani $\mathrm{f}$. sp. piperis. In: EMBRAPA. Centro de Pesquisa Agroflorestal da Amazônia Oriental (Belém, PA). Geração de tecnologia agroindustrial para o desenvolvimento do trópico úmido. Belém Embrapa-CPATU/JICA， 1996. p.109-124 (Embrapa-CPATU. Documentos, 85).

WELLER, D.M. Biological control of soil-borne plant pathogens in the rhizosphere with bacteria. Annual Review of Phytopathology, Palo Alto, v.23, p.379407, 1988

ZHANG, P.G.; SUTTON, J.C.; TAN, W.; HOPKIN, A.A. Gliocladium roseum reduces physiological changes associates with infection of black spruce seedlings by Botrytis cinerea. Canadian Journal of Plant Pathology, Guelph, v.18, p.7-13, 1996. 